\title{
EISCAT and ESRAD radars observations of polar mesosphere winter echoes during solar proton events on 11-12 November 2004
}

\author{
E. Belova, S. Kirkwood, and T. Sergienko \\ Swedish Institute of Space Physics, Box 812, 98128 Kiruna, Sweden \\ Correspondence to: E. Belova (belova@irf.se) \\ Received: 5 December 2012 - Revised: 24 May 2013 - Accepted: 29 May 2013 - Published: 3 July 2013
}

\begin{abstract}
Polar mesosphere winter echoes (PMWE) were detected by two radars, ESRAD at $52 \mathrm{MHz}$ located near Kiruna, Sweden, and EISCAT at $224 \mathrm{MHz}$ located near Troms $\varnothing$, Norway, during the strong solar proton event on 11-12 November 2004. PMWE maximum volume reflectivity was estimated to be $3 \times 10^{-15} \mathrm{~m}^{-1}$ for ESRAD and $2 \times 10^{-18} \mathrm{~m}^{-1}$ for EISCAT. It was found that the shape of the echo power spectrum is close to Gaussian inside the PMWE layers, and outside of them it is close to Lorentzian, as for the standard ion line of incoherent scatter (IS). The EISCAT PMWE spectral width is about $5-7 \mathrm{~m} \mathrm{~s}^{-1}$ at $64-67 \mathrm{~km}$ and $7-10 \mathrm{~m} \mathrm{~s}^{-1}$ at $68-70 \mathrm{~km}$. At the lower altitudes the PMWE spectral widths are close to those for the IS ion line derived from the EISCAT data outside the layers. At the higher altitudes the PMWE spectra are broader by $2-4 \mathrm{~m} \mathrm{~s}^{-1}$ than those for the ion line. The ESRAD PMWE spectral widths at $67-72 \mathrm{~km}$ altitude are $3-5 \mathrm{~m} \mathrm{~s}^{-1}$, that is, $2-4 \mathrm{~m} \mathrm{~s}^{-1}$ larger than ion line spectral widths modelled for the ESRAD radar. The PMWE spectral widths for both EISCAT and ESRAD showed no dependence on the echo strength. It was found that all these facts cannot be explained by turbulent origin of the echoes. We suggested that evanescent perturbations in the electron gas generated by the incident infrasound waves may explain the observed PMWE spectral widths. However, a complete theory of radar scatter from this kind of disturbance needs to be developed before a full conclusion can be made.
\end{abstract}

Keywords. Electromagnetics (Scattering and diffraction) Ionosphere (Ionosphere-atmosphere interactions) - Radio science (General or miscellaneous)

\section{Introduction}

Remarkable and strong radar mesospheric echoes called polar mesosphere summer echoes (PMSE) are detected in summertime in the polar regions. Discovered in the late 1970s/early 1980s (Czechowsky et al., 1979; Ecklund and Balsley, 1981), PMSE have been intensively studied for more than 30 years. It is now commonly accepted that PMSE are due to a combination of neutral atmospheric turbulence and charged nanometre-sized ice particles. For a review on PMSE see e.g. Rapp and Lübken (2004).

In the high-latitude mesosphere, another type of strongly enhanced radar return, different from PMSE, is sometimes found at altitudes below $80 \mathrm{~km}$ in the winter and equinox seasons. By analogy with PMSE these have been named polar mesosphere winter echoes, PMWE (Kirkwood et al., 2002b). PMWE have been studied with radars (e.g. Kirkwood et al., 2002a; Belova et al., 2005; Zeller et al., 2006), using in situ measurements by rockets (e.g. Lübken et al., 2006; Brattli et al., 2006) and using artificial heating of the mesospheric plasma with radio waves (Kavanagh et al., 2006; Belova et al., 2008; La Hoz and Havnes, 2008). It has been found that PMWE occurrence rates are much lower than those for summer echoes (Zeller et al., 2006), but PMWE can be as strong as PMSE, reaching volume reflectivity up to $10^{-12} \mathrm{~m}^{-1}$ at $50 \mathrm{MHz}$ (Stebel et al., 2004). Though ice particles cannot exist in the warmer winter mesosphere, heating experiments have shown the presence of smaller charged particles, presumably of meteoric smoke origin (Belova et al., 2008; La Hoz and Havnes, 2008).

So far two main hypotheses have been suggested to explain the winter echoes. The first one explains PMWE by neutral turbulence with or without the presence of small charged particles (Lübken et al., 2006; La Hoz and Havnes, 
Table 1. Parameters of the radars.

\begin{tabular}{lcc}
\hline Radar & ESRAD & EISCAT VHF \\
\hline Geographic coordinates & $67.87^{\circ} \mathrm{N} 21.10^{\circ} \mathrm{E}$ & $69.59^{\circ} \mathrm{N} 19.23^{\circ} \mathrm{E}$ \\
Operating frequency & $52 \mathrm{MHz}$ & $224 \mathrm{MHz}$ \\
Transmitter peak power & $72 \mathrm{~kW}$ & $1.5 \mathrm{MW}$ \\
Antenna 3-dB beam width & $6^{\circ}$ & $1.7^{\circ} \mathrm{NS} \times 1.2^{\circ} \mathrm{EW}$ \\
Antenna effective area & $3740 \mathrm{~m}^{2}$ & $5690 \mathrm{~m}^{2}$ \\
\hline
\end{tabular}

2008; Havnes et al., 2011). Another hypothesis suggests a non-turbulent origin of winter mesospheric radar echoes and involves infrasound waves propagated from below (Kirkwood et al., 2006).

Some observed features of PMWE cannot be explained by neutral air turbulence, with or without the presence of dusty particles. The most striking finding is that the strongest echoing structures move horizontally with the speed of sound rather than with speed of the background wind, the latter being expected for patches of turbulence (Kirkwood et al., 2006). On some occasions PMWE have been detected with two radars simultaneously: with the ESRAD $52 \mathrm{MHz}$ radar and the $224 \mathrm{MHz}$ European Incoherent Scatter radar (EISCAT) (e.g. Belova et al., 2005). The surprising feature of PMWE at $224 \mathrm{MHz}$ is that their spectral width appears to be about the same as for the incoherent scatter ion line spectra above and below the PMWE layer (Kirkwood et al., 2006; Kirkwood, 2007). The ion line spectral width is determined by the lifetime of highly damped ion-acoustic waves in the ionospheric plasma and has no relation to neutral turbulence.

This paper is based on observations of PMWE during the strong solar proton event on 10-12 November 2004 with the ESRAD and EISCAT VHF radars. We aim to make an accurate derivation and analysis of the spectral characteristics of PMWE layers, which might shed light on the generation mechanism of these echoes.

\section{PMWE observations on 10-12 November 2004 with the EISCAT and ESRAD radars}

ESRAD is an atmospheric radar situated at Esrange, in northern Sweden. The EISCAT facility is located near Troms $\varnothing$, Norway, about $200 \mathrm{~km}$ north of ESRAD. The main characteristics of ESRAD and the EISCAT VHF radar are summarised in Table 1. PMWE can be seen with ESRAD and the EISCAT VHF radar when extra ionisation of the D region of the ionosphere occurs due to precipitating energetic particles (Kirkwood et al., 2002a, b, 2006; Belova et al., 2005).

In November 2004 there was a strong solar proton event (SPE) (see e.g. the proton fluxes measured on the GOES satellites at www.swpc.noaa.gov/ftpmenu/index.html) when energetic particles of solar origin penetrated deeply into the Earth's atmosphere, ionised it and produced enhanced electron density. Both ESRAD and the EISCAT VHF radar were
Table 2. Parameters of the experiments.

\begin{tabular}{lcc}
\hline & ESRAD & EISCAT VHF \\
\hline Experiment name & fca_4500 & arc_dlayer \\
Pulse length (altitude resolution) & $600 \mathrm{~m}$ & $300 \mathrm{~m}$ \\
Pulse repetition frequency, Hz & 1300 & 741 \\
No. of bits in code & 8 & 64 \\
No. of code permutations & 2 & 128 \\
No. of coherent integrations & 16 & 1 \\
Lag resolution & $24.6 \mathrm{~ms}$ & $1.35 \mathrm{~ms}$ \\
Maximum lag & $25 \mathrm{~s}$ & $0.17 \mathrm{~s}$ \\
\hline
\end{tabular}

running during 10-12 November, and details of the operational modes are presented in Table 2.

The radar volume reflectivities were calculated for these three days as follows. For the EISCAT radars the volume reflectivity is defined as $\sigma_{0} \cdot N_{\mathrm{e}}$, where $\sigma_{0}=4.99 \times 10^{-29} \mathrm{~m}^{2}$ is the effective Thomson scattering cross-section per electron and $N_{\mathrm{e}}$ is the electron density (or equivalent electron density for the case of PMWE where the scattering mechanism is unknown) provided by the EISCAT GUISDAP software package. For the ESRAD radar the calculation procedure is more complicated and based on calibration of the radar against radiosondes as described by Kirkwood et al. (2010). Following this paper one can express ESRAD volume reflectivity $\eta$ at altitude $h$ as

$\eta=C_{\mathrm{cal}} \cdot S \cdot h^{2}$

where $S$ is the echo received power in arbitrary units and $C_{\text {cal }}$ is the calibration coefficient which is a function of experiment and radar parameters. $C_{\text {cal }}$ is constant for the given radar and experiment and can be defined by comparing volume reflectivity in the troposphere and the mean vertical gradient of generalised potential refractive index $M$ determined from radiosonde data (see for details Kirkwood et al., 2010). It can be shown that

$C_{\text {cal }}=\frac{64(2 \ln 2)}{(4 \pi)^{2}} \frac{C_{0} \cdot G \cdot M^{2}}{S_{\text {tropo }} \cdot h^{2}}$,

where $S_{\text {tropo }}$ is received power from the upper troposphere/lower stratosphere in arbitrary units, $G$ is the antenna gain, and $C_{0}$ is the constant of proportionality between the radar scatter strength and $M^{2}$, which was found by Kirkwood et al. (2010) to be $1.5 \times 10^{-3}$ for ESRAD. The antenna gain can be estimated from the radar transmitting beam width $\theta_{\mathrm{T}}$ using the approximate relation

$G=\frac{\pi^{2}}{4 \theta_{\mathrm{T}}^{2}}$

For calculations of $M^{2}$, we used data from the regular radiosondes launched at 12:00 UT on 10-12 November 2004 in Sodankyla, Finland, $350 \mathrm{~km}$ SE from ESRAD. 

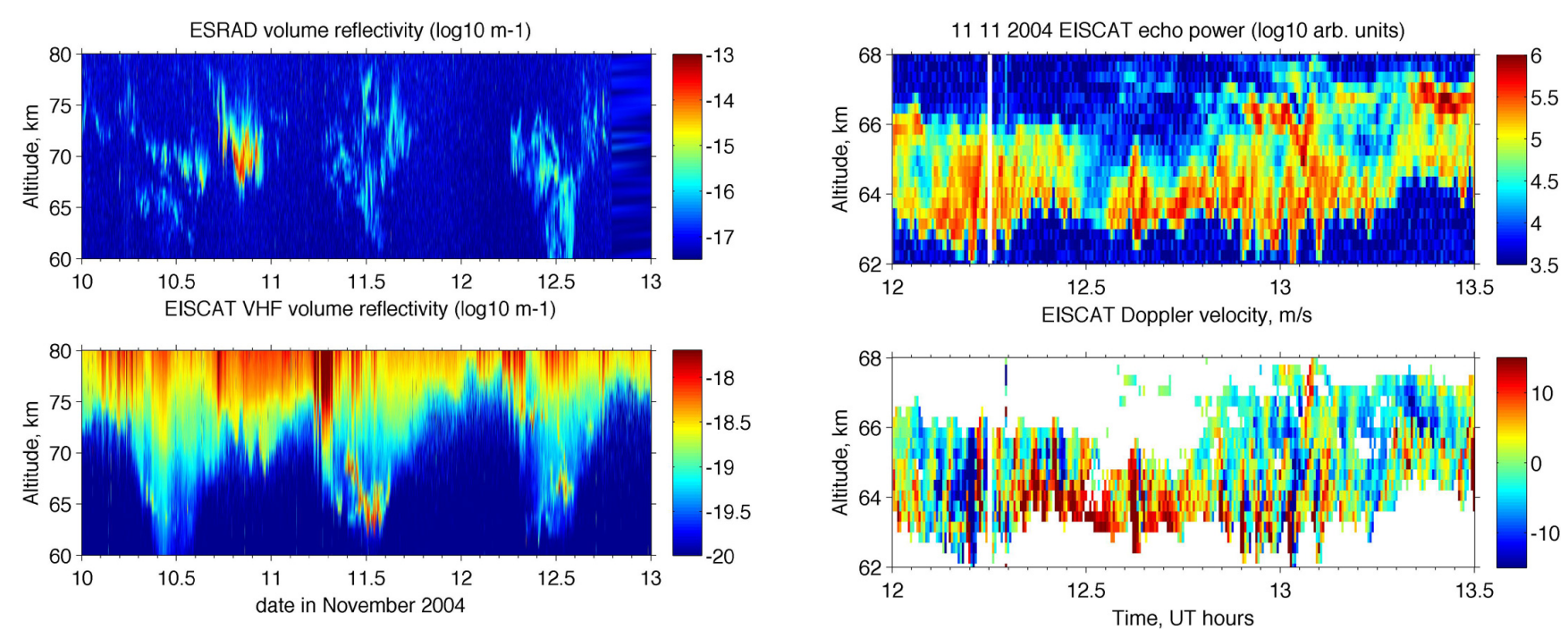

Fig. 1. Time-altitude maps of ESRAD (upper panel) and EISCAT VHF volume reflectivities during the SPE on 10-12 November 2004 .

The top panel of Fig. 1 shows ESRAD volume reflectivity for 10-12 November. PMWE are seen as very intermittent, variable, narrow layers. PMWE vary during the day: they appear at lower altitudes during daytime, then move to higher altitudes during evening hours and disappear by midnight. Kirkwood et al. (2002a, b) suggested that PMWE diurnal variations are related to diurnal variations of the free electrons which are responsible for radar scatter. Electrons dominate over negative ions during daytime, when negative ions are photo-dissociated. With decreasing solar elevation the negative ions are reformed, starting from the lower heights, reducing the number of free electrons. (Intensification of PMWE at 17:00-22:00 UT on 10 November can be related to extra ionisation due to energetic particle precipitation.) The bottom panel presents a time-altitude plot of EISCAT volume reflectivity measured during the same time. The thin layers of PMWE are seen against the background of slightly enhanced radar backscatter due to the electron density caused by solar proton precipitation. The diurnal variation of the background electron density, with its increase at lower heights during daytime and crucial reduction during nighttime, is clearly seen on this panel.

Kirkwood et al. (2006) studied PMWE events on 10 November 2004 when the signal measured with the ESRAD radar was at its strongest, allowing full correlation analysis (Briggs, 1985) to be applied. In this paper we concentrate on the next two days, 11 and 12 November, during daytime (interval from 08:00 UT to 13:00 UT, when the Sun is above the horizon at mesospheric heights), where the strongest echoes were observed with the EISCAT radar.

Fig. 2. EISCAT radar echo power (upper panel) and Doppler velocity (lower panel) on 11 November 2004.

\subsection{EISCAT data analysis}

For the EISCAT experiment the autocorrelation functions (ACFs) were formed from 127 lags, with a lag increment of $1.35 \mathrm{~ms}$ and recorded every $5 \mathrm{~s}$. After integration over $20 \mathrm{~s}$ the MATLAB FFT function was used for calculation of the spectra. When analysing the Doppler shifts we found that waves with periods of about 1 min are present in the EISCAT data. As an example, in Fig. 2 the signal power (upper panel) and the Doppler velocity (lower panel) for 12:00-13:30 UT on 11 November 2004 are presented with $20 \mathrm{~s}$ time resolution. Both quantities show oscillations with periods of 60 $90 \mathrm{~s}$ which are more clearly seen at around 13:00 UT, and they are probably a signature of waves. The Doppler velocity changes from positive to negative and back again over about a 1-min interval, which will lead to an apparent spectral width broadening when spectra are integrated over $20 \mathrm{~s}$. However, in order to have well-defined spectra from which a reliable estimation of spectral width is possible, we need an even longer integration time of several minutes. Following Strelnikova and Rapp (2010) we decided to make our analysis using ACFs. The description of the EISCAT ACF data analysis is given in Appendix A. As is shown there, we have to use two different methods for integration of ACFs over several $5 \mathrm{~s}$ data records for PMWE signal and for background incoherent scatter (IS). However in both cases we use the magnitude of the ACFs which, unlike their real and imaginary parts, does not oscillate with Doppler velocity (Eqs. A3 and A4) and is mainly determined by the decay/correlation time of the signal.

It appears that, after integration over $10 \mathrm{~min}$, the magnitudes of ACFs are still noisy, especially for the background signal beyond PMWE. Therefore, before applying the Fourier transform to them, in order to determine signal 

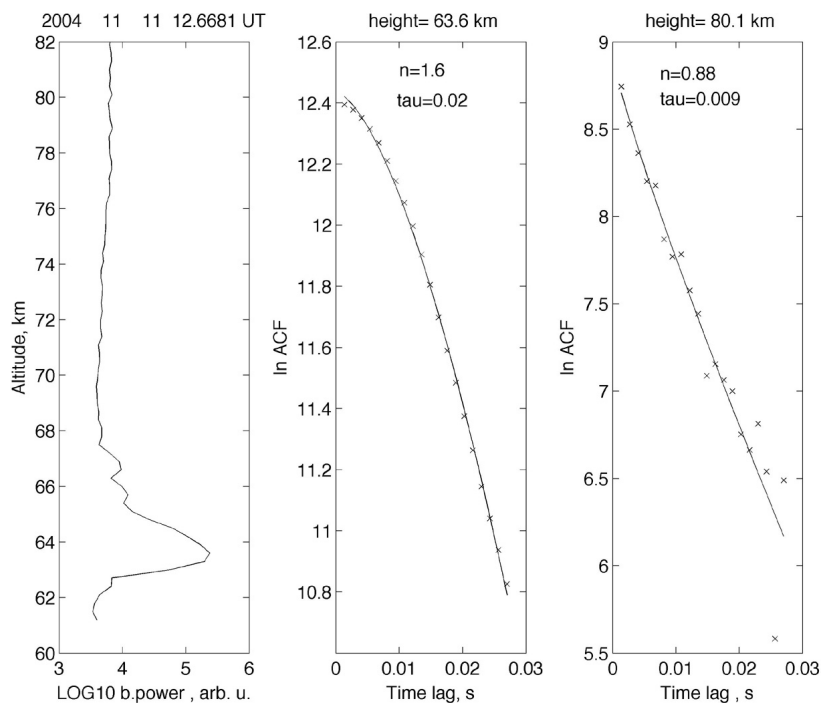

Fig. 3. Profile of EISCAT radar backscattered power (left panel), experimental (crosses) and fitted (solid line) ACFs at two altitudes: $63.6 \mathrm{~km}$ (middle panel), where the maximum of PMWE power was observed, and $80.1 \mathrm{~km}$ (right panel), where the EISCAT radar measured background incoherent scatter. The parameters of fit: power of exponent $\mathrm{n}$ and decay time tau in seconds are shown in the panels.

power spectra and estimate the spectral widths, we approximated the absolute value of ACFs for the EISCAT backscattered signals as follows (Jackel, 2000; Moorcroft, 2004; Strelnikova and Rapp, 2010):

$\operatorname{ACF}(\tau)=\mathrm{ACF}_{\tau=0} \cdot \exp \left\{-\left(\tau / \tau_{\mathrm{c}}\right)^{n}\right\}$,

where $\mathrm{ACF}_{\tau=0}$ is the magnitude of the autocorrelation function at zero time lag ( $=$ backscattered power after subtraction of noise), $\tau$ is the time lag, $\tau_{\mathrm{c}}$ is the decay/correlation time and $n$ characterises the shape of the autocorrelation function and hence the spectrum. Lorentzian and Gaussian spectra correspond to ACFs with $n=1$ and 2, respectively. For such spectra there are also analytical relationships between spectral width and ACF decay time $\tau_{\mathrm{c}}$ as follows:

$$
\begin{aligned}
& w_{\mathrm{G}}=\frac{\sqrt{\ln (2)}}{\pi \cdot \tau_{\mathrm{c}}} \\
& w_{\mathrm{L}}=\frac{1}{2 \pi \cdot \tau_{\mathrm{c}}},
\end{aligned}
$$

where $w_{\mathrm{G}, \mathrm{L}}$ are the half-maximum half-width in $\mathrm{Hz}$ for the Gaussian and Lorentzian spectra, respectively. Note that, for the same ACF decay times, the Gaussian spectrum is about 1.7 times wider than the Lorentzian one.

All echoes on 11 and 12 November 2004 were divided into two bins according to the deviation of their strength from the mean value calculated by averaging over $81-86 \mathrm{~km}$ altitude, where presumably only incoherent echo occurs. When this deviation is above a chosen threshold, this echo is associated with a PMWE layer, while an echo power below the thresh-
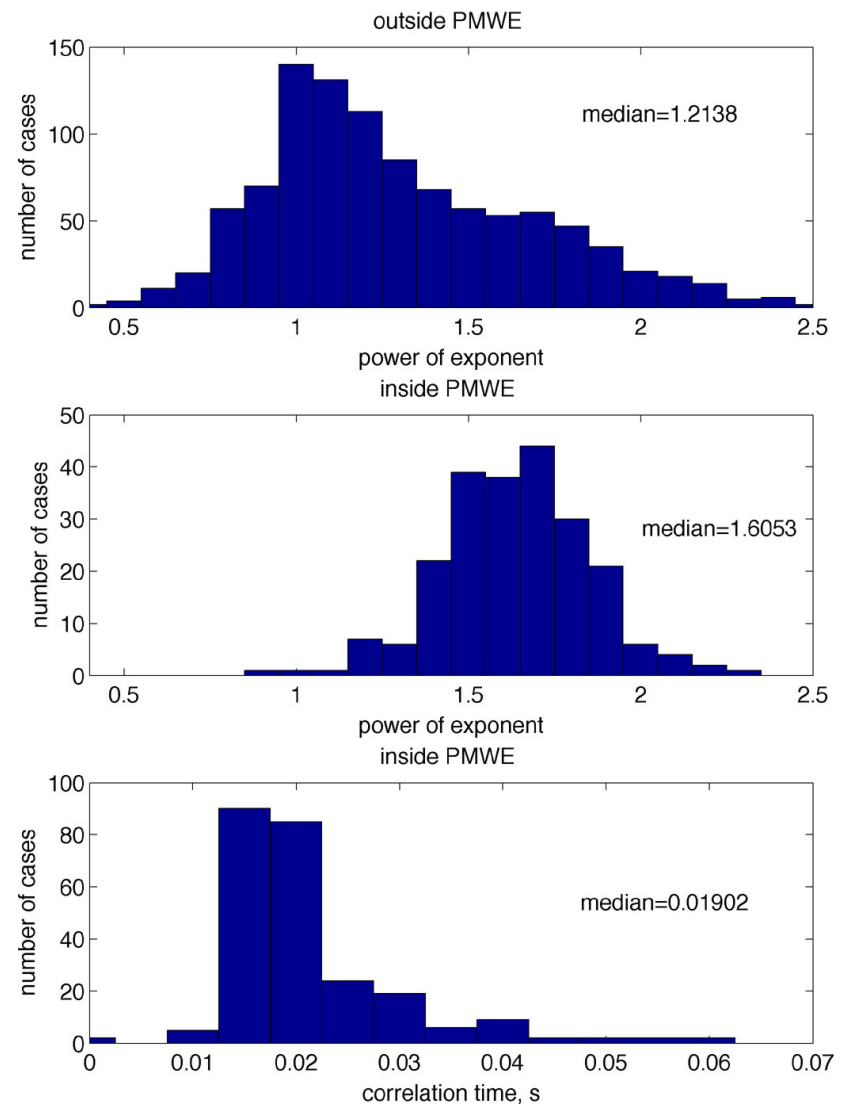

Fig. 4. The histograms for the power of exponent for ACF fit outside (upper panel) and inside (middle panel) PMWE and for correlation time inside PMWE (lower panel) measured by the EISCAT VHF radar on 11 November 2004. Median values of power of exponent and correlation time are shown on the respective panels.

old corresponds to (incoherent) backscatter from the background plasma. For the PMWE data we firstly calculated absolute values of ACFs recorded with $5 \mathrm{~s}$ time resolution and then averaged them over 10 min (method 1 in Appendix A). For the ACFs outside PMWE layers we first used averaged complex ACFs over the same 10-min intervals and then took absolute values (method 2 in Appendix A). After averaging we fitted for the first 20 lags the logarithm of the resulting ACFs by a power function as follows:

$\ln (\mathrm{ACF})=x_{1}-\left(\frac{\tau}{x_{2}}\right)^{x_{3}}$,

where $x_{1}, x_{2}$ and $x_{3}$ are estimates of $\ln \left(\mathrm{ACF}_{\tau=0}\right), \tau_{\mathrm{c}}$ and $n$, respectively. In order to find the best fit, we minimised the mean square error between the logarithm of the fitted and experimental ACFs. ACF values at zero lag are less reliable due to the presence of white noise and were excluded from fitting.

In Fig. 3 we present an example of experimental and fitted ACFs at two altitudes: $63.6 \mathrm{~km}$, where the maximum of PMWE power was observed, and $80.1 \mathrm{~km}$, where the 

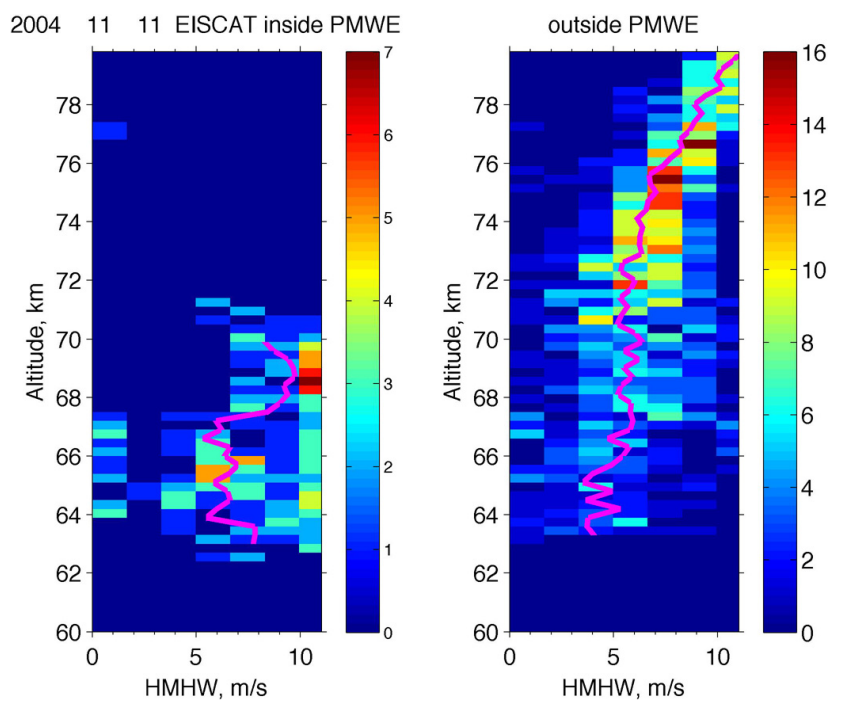

Fig. 5. Histograms of half-maximum half-width (HMHW) of power spectra at each altitude inside (left panel) and outside (right panel) PMWE measured by the EISCAT VHF radar on 11 November 2004. Colour indicates number of cases when HMHW has a value lying in the particular spectral width bin. Profiles of median HMHWs are indicated in magenta.

EISCAT radar measured background incoherent scatter. We see that the ACF for PMWE is smooth and very closely approximated by the exponential function with power $n=1.6$, i.e. close to the Gaussian function, which would have $n=2$. In contrast, the ACF measured at $80.1 \mathrm{~km}$ is rather noisy, and its approximation is not perfect. The best fit for the exponential function has a power $n$ of about 0.9 , i.e. close to $n=1$, which corresponds to incoherent scatter with the Lorentzian spectral shape.

In order to study the difference in spectral shapes for PMWE and for background incoherent scatter, all echoes were divided into two bins as described before. Figure 4 shows the histograms for the power of the exponent inside and outside PMWE for 11 November. In most cases the powers of the exponent inside and outside the PMWE layers are larger and smaller than 1.5 , respectively. Thus, indeed the ACFs inside and outside PMWE layers have different shapes. In Fig. 4 the histogram for the correlation time $\tau_{\mathrm{c}}$ inside PMWE is also presented. The majority of PMWE correlation times are between 10 and $40 \mathrm{~ms}$, with a median value of $19 \mathrm{~ms}$.

Because the powers of the exponent of the fits are not exactly equal to 1 or 2 , we cannot directly derive the spectral widths from the decay times by applying Eqs. (5) or (6). Therefore, we first apply the Fourier transform (the MATLAB FFT function) to the exponential fits of ACFs and then deduce spectral widths for the resulting power spectra. From this point on the spectral width means the half-maximum half-width of the power spectra of the signal.

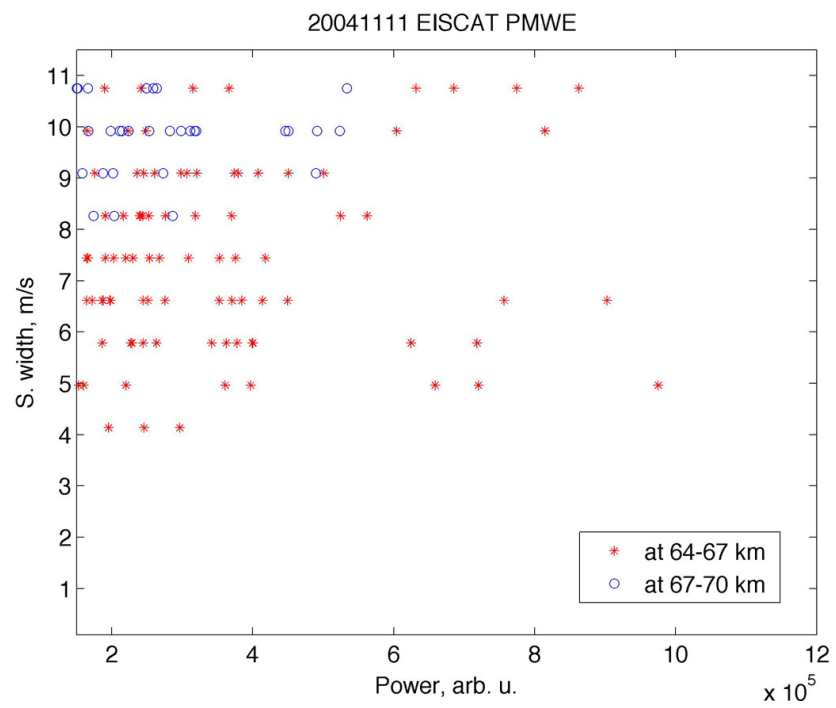

Fig. 6. Scatter plot of EISCAT PMWE spectral width versus backscattered power at $64-67 \mathrm{~km}$ (red *) and $67-70 \mathrm{~km}$ (blue o) altitude for 11 November 2004.

Figure 5 presents the results for fitting for 11 November when PMWE measured by EISCAT were especially strong and long-lasting. The left and right panels present the altitude profiles of the spectral width distributions inside and outside PMWE layers, respectively. One can see that inside the PMWE layers the median spectral widths are $5-10 \mathrm{~m} \mathrm{~s}^{-1}$ and that they are somewhat larger that those at the same altitudes but outside the layers. The spectral width for the background plasma increases slowly from 4 to $6 \mathrm{~m} \mathrm{~s}^{-1}$ in the lower altitude range of $64-74 \mathrm{~km}$ and then grows more quickly up to $11 \mathrm{~m} \mathrm{~s}^{-1}$ by $80 \mathrm{~km}$. In Fig. 6 the scatter plot of the spectral widths inside the PMWE layers versus backscattered power is shown for $64-67 \mathrm{~km}$ and $67-70 \mathrm{~km}$ altitudes. There is no obvious dependence of the PMWE spectral width on their strength for both altitude ranges evident in this figure.

\subsection{ESRAD data analysis}

For the ESRAD radar, firstly, the full correlation analysis (FCA) was applied (Briggs, 1985) using raw data with $25 \mathrm{~ms}$ time resolution, sampled over $64 \mathrm{~s}$ time intervals. Intrinsic scatterer lifetime $T_{1 / 2}$ (time to decay to half power) was calculated for each $64 \mathrm{~s}$ interval. Then spectral widths were calculated according to the formula (Holdsworth et al., 2001)

$w_{\mathrm{esrad}}=\frac{\ln 2 \cdot \lambda_{\mathrm{r}}}{2 \pi T_{1 / 2}}$,

where $w_{\text {esrad }}$ is the half-power half-spectral width in $\mathrm{ms}^{-1}$, and $\lambda_{\mathrm{r}}$ is the ESRAD wave length.

(From the Doppler shifts vertical winds were also derived. They have a signature of waves with a period of $1 \mathrm{~h}$ and 

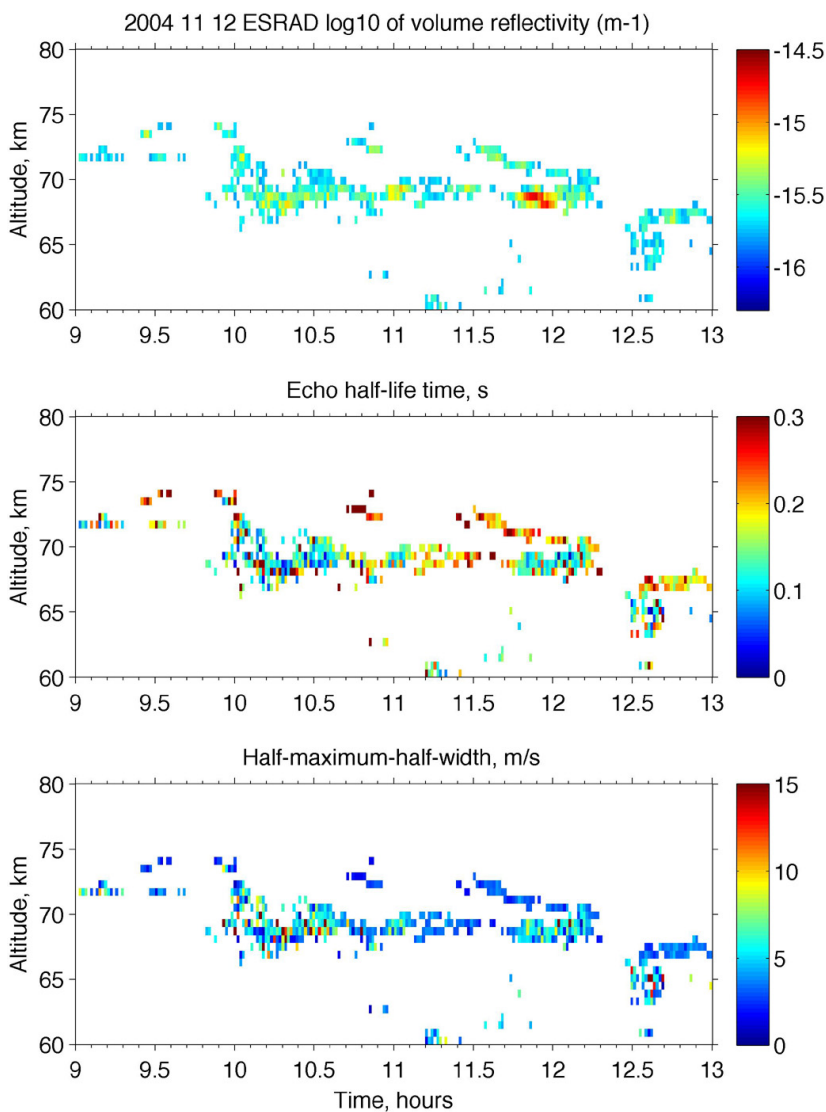

Fig. 7. The altitude-time maps of the ESRAD radar volume reflectivity (top panel) and the echo half-life time deduced from full correlation analysis (middle panel) and the corresponding halfmaximum half-width of power spectra (lower panel) for 12 November 2004.

longer (not shown), i.e. these waves cannot affect the spectral width results.)

The results for 12 November 2004, when the ESRAD echoes were particularly strong, are shown in Fig. 7. Volume reflectivity presented on the upper panel reaches its maximum of $3 \times 10^{-15} \mathrm{~m}^{-1}$ at about 11:50 UT. Half-maximum half-width of the spectrum varies from 1 up to $8 \mathrm{~ms}^{-1}$. The better presentation of dependencies of echo spectral widths on altitude and echo strength is in Fig. 8, where the histograms for the spectral widths and their median values are shown. There is no clear dependence of spectral width either on the altitude or on the echo strength expressed in the radar volume reflectivity, and the median spectral widths are 3$5 \mathrm{~m} \mathrm{~s}^{-1}$. The results for 11 November 2004 (not shown) are similar to those for the next day in regard to absence of altitude and echo strength dependencies and the median values.

Experimental spectral widths should in general be corrected for instrumental effects such as beam broadening. The beam broadening $w_{\text {beam }}$ can be written as (Hocking, 1985)
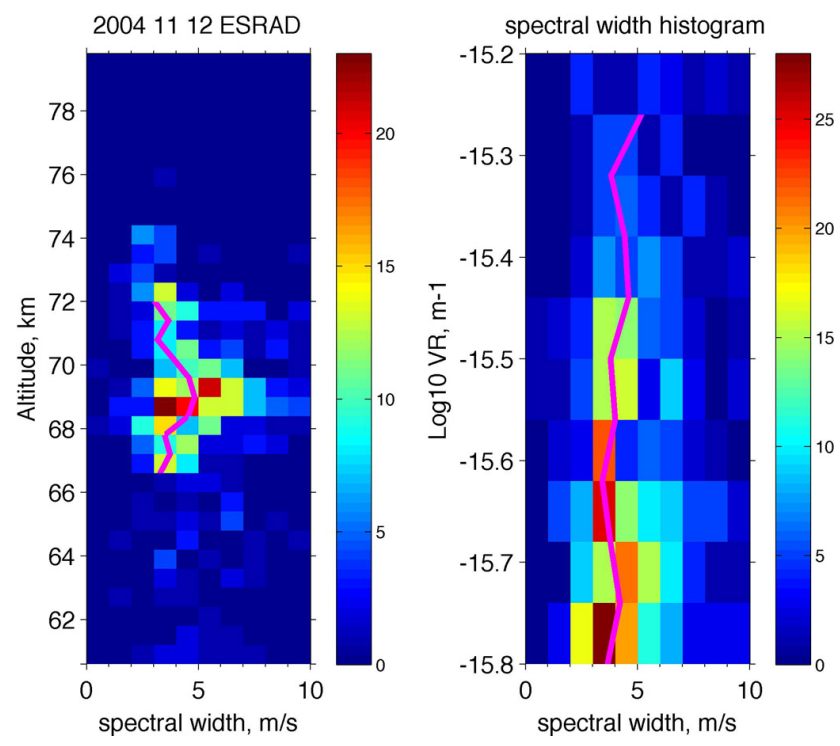

Fig. 8. Histograms of half-maximum half-width of power spectra at each altitude (left panel) and each value of logarithm of the ESRAD volume reflectivity (right panel) for PMWE measured on 12 November 2004. Colour indicates number of cases when halfmaximum half-width has a value in the particular spectral width bin. The median HMHWs are indicated in magenta.

$w_{\text {beam }}\left(\mathrm{m} \mathrm{s}^{-1}\right)=\theta_{1 / 2} \cdot V_{\mathrm{hor}}=\frac{1}{2 \sqrt{2}} \cdot \theta \cdot V_{\mathrm{hor}} \approx 0.35 \cdot \theta \cdot V_{\mathrm{hor}}$,

where $\theta_{1 / 2}$ is the half-maximum half-width of the effective radar beam (two ways), $\theta$ is the $3 \mathrm{~dB}$ full beam width in radians and $V_{\text {hor }}$ is the horizontal wind speed. In our experiments the horizontal wind was not measured; however, we can assume it to be up to $60 \mathrm{~m} \mathrm{~s}^{-1}$ (Müllemann and Lübken, 2005). Then the maximum beam broadening is $2.2 \mathrm{~m} \mathrm{~s}^{-1}$ for ESRAD. However, correction for the beam broadening is applied to the Doppler method and does not affect the results of the full correlation analysis based on the spaced antenna technique. For the EISCAT VHF radar the maximum beam broadening is at most $0.6 \mathrm{~m} \mathrm{~s}^{-1}$ and can be neglected compared to the measured spectral width values of $4-11 \mathrm{~m} \mathrm{~s}^{-1}$.

\section{Experimental and theoretical spectral widths}

Spectral width (half-maximum half-width) of the IS ion line for the diffusion limit, for normal molecular/cluster ions, can be expressed according to the formula (Kofman et al., 1984)

$w_{\text {incoh }}\left(\mathrm{m} \mathrm{s}^{-1}\right)=\frac{4 \pi k_{\mathrm{B}} T\left(2\left(1+\lambda^{-}\right)+\alpha^{2}\right)}{\lambda_{\mathrm{r}} m_{\mathrm{i}} v_{\text {in }}\left(1+\alpha^{2}\right)}$,

where $k_{\mathrm{B}}$ is Boltzmann's constant, $T$ is neutral temperature (assumed to be equal to the ion and electron temperatures in this altitude region), $\lambda_{\mathrm{r}}$ is radar wavelength, $m_{\mathrm{i}}$ is the mean 

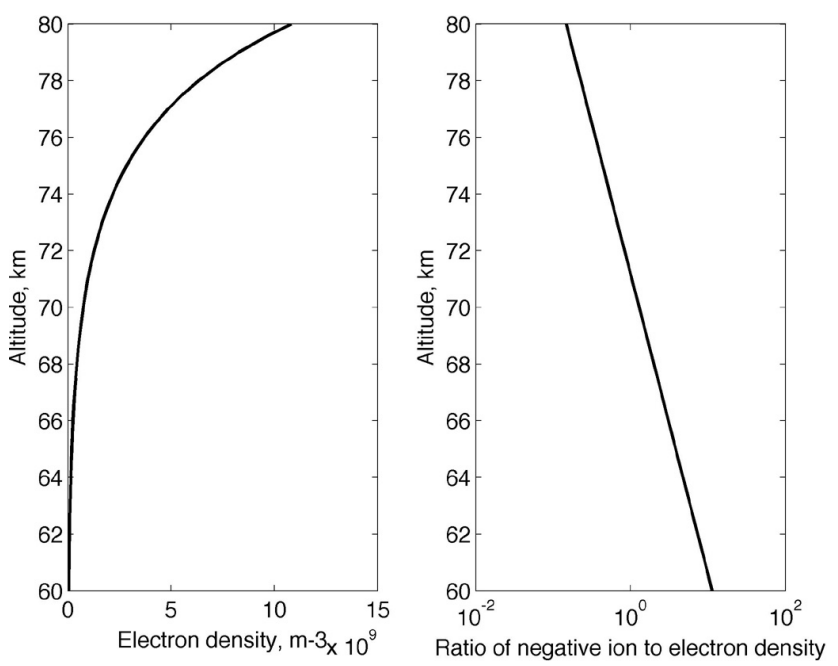

Fig. 9. Profiles of the modelled electron density (left panel) and the ratio of negative ion to electron density (right panel).

positive ion mass, $v_{\text {in }}$ is the ion-neutral collision frequency, $\lambda^{-}$is the ratio of negative ion density to electron density and $\alpha=4 \pi \cdot \lambda_{\mathrm{D}} / \lambda_{\mathrm{r}}$ with the Debye length $\lambda_{\mathrm{D}}$ as follows:

$\lambda_{\mathrm{D}} \approx 69 \sqrt{T / N_{\mathrm{e}}}$

Here $N_{\mathrm{e}}$ is the electron density. $\lambda^{-}$can be larger than 1 at altitudes below $75 \mathrm{~km}$ during winter conditions (e.g. Brasseur and Solomon, 1986).

According to Banks and Kockarts (1973), and with assumptions made by Mathews (1978), the ion-neutral collision frequency can be written as follows:

$v_{\text {in }}=2.6 \times 10^{-9} \cdot \frac{N}{m_{\mathrm{i}}}\left(1.03 \mu_{\mathrm{i}, \mathrm{N}_{2}}^{0.5}+0.28 \mu_{\mathrm{i}, \mathrm{O}_{2}}^{0.5}\right)$,

where $N$ is the neutral number density and $\mu_{\mathrm{i}, X}$ are the reduced mass of ions and molecules of $\mathrm{N}_{2}$ or $\mathrm{O}_{2}$. For $m_{\mathrm{i}}=$ $31 \mathrm{amu}$ Eq. (12) can be reduced to $v_{\text {in }} \approx 4.2 \times 10^{10} \cdot N$.

We calculated $w_{\text {incoh }}$ for the $60-80 \mathrm{~km}$ altitude range using Eq. (10). The electron density profile was taken from the EISCAT data for 11 November 2004 analysed by the EISCAT software package GUISDAP, averaged over the interval from 09:00 UT to 09:15 UT, when PMWE were absent, and then smoothed by an exponential fit. For $\lambda^{-}$we used an exponential profile with $\lambda^{-}=200$ at $50 \mathrm{~km}$ and $\lambda^{-}=1$ at $72 \mathrm{~km}$. This profile may be representative for daytime conditions for equinox seasons (Kirkwood and Osepian, 1995). Both model profiles for $N_{\mathrm{e}}$ and $\lambda^{-}$are shown in Fig. 9. Neutral temperature and density were taken from the MSISE90 model (Hedin, 1991). The calculated profiles of ion line spectral width for 52 and $224 \mathrm{MHz}$ are presented in Fig. 10. As expected for IS spectra, the spectral widths increase with height starting from $66-68 \mathrm{~km}$ because $v_{\text {in }}$ decreases with height. The behaviour of spectral widths at lower heights is

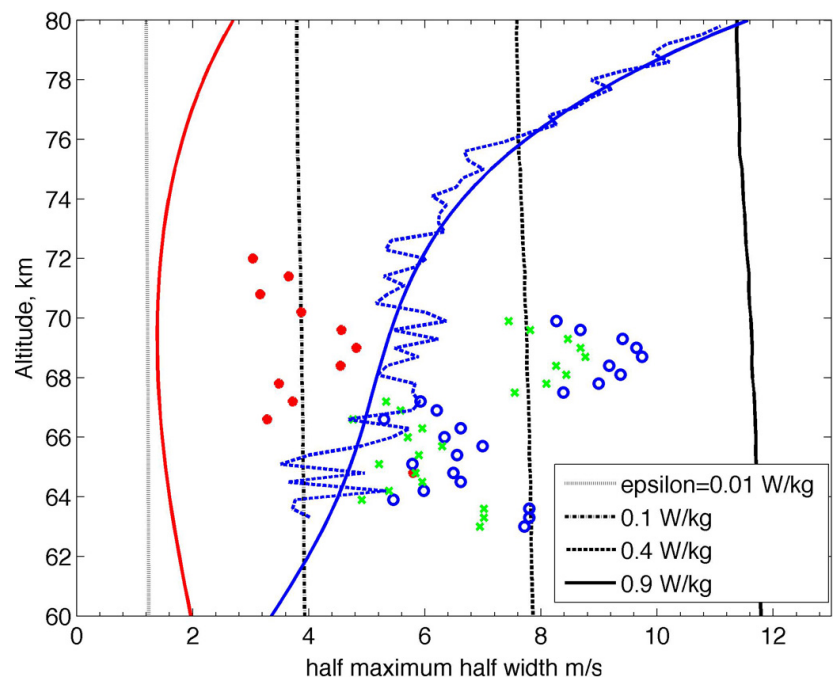

Fig. 10. Profiles of modelled half-maximum half spectral widths for incoherent scatter ion line at $224 \mathrm{MHz}$ (blue), at $52 \mathrm{MHz}$ (red) and for turbulent scatter (black). Different black curves correspond to different values of turbulent dissipation rates $\varepsilon$ shown in the text box. Median spectral widths of PMWE are shown by the following symbols: red $*$ correspond to the ESRAD measurements on 12 November 2004, and green $\mathrm{x}$ and blue o to the EISCAT data on 11 November 2004 with and without correction for maximum spectral broadening due to averaging and waves, respectively.

affected by the presence of negative ions there, and hence depends on the model of $\lambda^{-} . \alpha^{2} \ll 1$ for ESRAD and the D region conditions, and hence $w_{\text {incoh }}$ is inversely proportional to the radar wavelength. This is also valid for the EISCAT VHF radar for altitudes above about $70 \mathrm{~km}$. There the spectral width for the EISCAT VHF radar is about 4 times larger than that for ESRAD $\left(\lambda_{\text {esrad }} / \lambda_{\text {eiscat }} \approx 4.3\right)$. In turn, for the EISCAT radar and the lower heights, $\alpha^{2} \sim 1$ and the term $1+\alpha^{2}$ becomes important in the denominator on the righthand side of Eq. (10). Then the ratio of ion line spectral widths for the EISCAT and ESRAD radars decreases to about 2 or less.

Figure 10 also presents the experimental spectral width profiles outside PMWE derived from the EISCAT data for 11 November. When comparing them to the modelled ion line spectral widths, one can see that they agree with each other well not only qualitatively but also quantitatively. They both increase with altitude in a similar way and have values of about $5 \mathrm{~ms}^{-1}$ at $70 \mathrm{~km}$ and $11 \mathrm{~m} \mathrm{~s}^{-1}$ at $80 \mathrm{~km}$. Thus we can believe that the spectral widths were correctly derived from the EISCAT data.

In Fig. 10 we also show PMWE median spectral widths derived from the EISCAT data for 11 November and ESRAD data for 12 November. The EISCAT spectral widths were calculated from the data without correction (blue circles) and with correction (green crosses) for maximum spectral broadening of $9 \%$ as estimated in Appendix A. At $64-68 \mathrm{~km}$ 
altitude the EISCAT corrected spectral widths inside PMWE layers are close to those for the ion line. However, below $64 \mathrm{~km}$ and at $68-71 \mathrm{~km}$, the PMWE spectral widths are 2$4 \mathrm{~m} \mathrm{~s}^{-1}$ larger than those for the ion line at the same altitudes. A similar situation is seen for PMWE spectral widths derived from ESRAD data: their values at altitudes of $67-72 \mathrm{~km}$ are larger by $2-4 \mathrm{~m} \mathrm{~s}^{-1}$ than those for IS at $52 \mathrm{MHz}$ at the same altitudes.

Lübken et al. (2006) have suggested that PMWE are of turbulent origin. If so, then the spectral width $w_{\text {turb }}$ of such echoes is related to fluctuating turbulent velocity $V$ and can be expressed via the turbulent dissipation rate $\varepsilon$ as (Hocking, 1985)

$w_{\text {turb }}^{2}=2 \ln 2 \cdot V^{2} \approx 1.4 \cdot \frac{1}{C} \cdot \frac{\varepsilon}{\Omega} \approx 2.9 \cdot \frac{\varepsilon}{\Omega}$,

where we have used $C=0.49$ (Weinstock, 1981; Hocking, $1996)$ and $\Omega$ is the buoyancy angular frequency. We have calculated $w_{\text {turb }}$ for $\varepsilon=0.01,0.1,0.4$ or $0.9 \mathrm{~W} \mathrm{~kg}^{-1}$ assuming it does not change for the $60-80 \mathrm{~km}$ altitude range. $\Omega$ was calculated using the MSISE-90 model (Hedin, 1991). The altitude profiles of the modelled turbulent spectral widths are shown in Fig. 10. If PMWE observed on 11 and 12 November are interpreted as turbulent echoes, then they appear to correspond to turbulent dissipation rates of $60-700 \mathrm{~mW} \mathrm{~kg}^{-1}$. However this must be considered more carefully, which will be done in the next section.

\section{Discussion}

The results of the EISCAT and ESRAD PMWE experiments and modelling can be summarised as follows:

1. PMWE spectral widths for the EISCAT measurements are sometimes the same as the IS ion line spectral widths at the same heights, but sometimes significantly higher. For PMWE measured by ESRAD the spectral widths are higher than for IS ion line widths computed using the model.

The IS ion line is formed due to scattering of the radar signal on perturbations of electron density caused by ion-acoustic waves. In the ionospheric plasma these waves are excited by the thermal fluctuations of ions. Electrons, due to the ambipolar electric field, follow the ion fluctuations. These density oscillations propagate in the plasma (due to action of the electrical field and ion thermal diffusion) as longitudinal waves with the ion-acoustic speed

$V_{\text {ia }}=V_{\text {ith }}\left(1+T_{\mathrm{e}} / T_{\mathrm{i}}\right)^{1 / 2}$,

where $V_{\text {ith }}$ is the ion thermal velocity.

For mesospheric altitudes where ion-neutral collisions play a role, the ion density fluctuation, once formed, decays due to collisions and hence does not propagate. Thus the relaxation of such perturbations of scale $\Delta z$ is determined by the diffusion speed as $V_{\mathrm{de}}=D_{\mathrm{ep}} / \Delta z$ (Mathews and Tanenbaum, 1981), where $D_{\text {ep }}$ is the electron-plasma diffusion coefficient.

In application to the power spectrum of the radar wave scattered from the ionospheric plasma for the lower frequency range - that is, the ion line - there are two ionacoustic maxima at velocities $\pm V_{\text {ia }}$ for the so-called "wave limit", when the ion-neutral collision frequency is not too high, or one Lorentzian-shaped central maximum, with width equal to $V_{\mathrm{de}}$, for the diffusion limit. For the EISCAT VHF radar and the real ionosphere the diffusion limit is valid for heights below, say, $100 \mathrm{~km}$. The power spectrum in the wave limit has a sophisticated shape described by full IS theory (Dougherty and Farley, 1960). For the large damping due to collisions with neutrals the edges of the spectrum are suppressed and the shape is reduced to a simpler Lorentzian as we have observed at altitudes outside PMWE.

An acoustic wave in the neutral gas excited e.g. at the lower heights can propagate to the mesosphere, where some neutral molecules become ionised (e.g. Blanc, 1985; Drob et al., 2003). There the fluctuations in the neutral density are closely connected to the ion fluctuations via frequent collisions. Again, ion fluctuations are transferred to the electrons due to the ambipolar electric field. Thus we can also call these waves ion-acoustic ones. However there is a clear difference between these waves and those described earlier. The former are spontaneously excited plasma waves, and the latter are forced waves in plasma. For collision-dominated plasma in the mesosphere (diffusion limit) the former ones are highly damped due to ion-neutral collisions. In contrast, the latter ones are excited due to collisions. Therefore the power spectrum of radar signal scattered from electron irregularities of half-radar-length scale (Bragg scale) caused by this wave might differ from the Lorentzian spectrum of highly damped ion-acoustic waves. One would expect that there would be two maxima as for case of no collisions, located at about $\pm 330 \mathrm{~m} \mathrm{~s}^{-1}$. These maxima cannot be seen with the acr_dlayer experiment for the EISCAT VHF radar, which has a maximum resolved velocity of $240 \mathrm{~m} \mathrm{~s}^{-1}$. Thus we cannot see incident acoustic waves.

Hocking (2003) has proposed that when incident acoustic waves are partially reflected from sharp vertical gradients of e.g. temperature or wind, evanescent perturbations are formed in the neutral gas in the vicinity of the reflecting boundary. They were termed viscosity waves. These waves are highly damped and their perturbations exist only in narrow layers. Via ion-neutral collisions and the action of the ambipolar electric field, perturbations in the electron density can be excited by these viscosity waves and could form highly aspect-sensitive scattering layers for the radar waves. Perturbations at the length scale matching the radar Bragg length would be seen as radar echoes. Kirkwood et al. (2006) has proposed PMWE to be due to scatter from the evanescent perturbations in electron density generated by partial reflection of infrasound waves. Because these evanescent 
disturbances are excited by incident acoustic waves in the vicinity of the border formed by a sharp gradient, their "source" moves along the border with the acoustic velocity. Indeed, high horizontal velocities up to $500 \mathrm{~m} \mathrm{~s}^{-1}$ were measured using ESRAD for the case of strong PMWE occurring before midnight on 10 November 2004 (Kirkwood et al., 2006). (Unfortunately, for 11 and 12 November we cannot derive horizontal velocities using the full correlation analysis because the echo strength was relatively low.)

As stated above, in order for the evanescent perturbation to be seen by a radar, its "wavelength" has to match the radar Bragg length $\left(=\lambda_{\mathrm{r}} / 2\right)$. Then, based on the dispersion relation for the viscosity waves (Hocking, 2003), which was modified for plasma, Kirkwood et al. (2006) showed that for a radar with wave length $\lambda_{\mathrm{r}}$ all incident acoustic waves with period $T_{\mathrm{a}}$ satisfying the equation $\lambda_{\mathrm{r}}=4\left(\pi \nu S_{\mathrm{c}} T_{\mathrm{a}}\right)^{0.5}$ can produce effective scattering structures (evanescent disturbances) in the electron gas. Here $v$ is the air kinematic viscosity and $S_{\mathrm{c}}$ is the Schmidt number $\left(S_{\mathrm{c}}<1\right.$ with the presence of significant number of negative ions, i.e. when $\lambda^{-}>1$ ). From Fig. 14 of Kirkwood et al. (2006), one can see that appropriate periods of acoustic waves at $65-75 \mathrm{~km}$ altitude range are $20-200 \mathrm{~ms}$ for EISCAT radar and $0.3-5 \mathrm{~s}$ for ESRAD, and these periods decrease with altitude. Then the evanescent fluctuations should decay on the timescale which is shortest between the electron-plasma diffusion time, as in the case of thermally induced ion-acoustic waves, and the "evanescent" time, i.e. the period of incident acoustic waves. From Fig. 10 we see for EISCAT that, at $64-67 \mathrm{~km}$ altitudes, the PMWE spectral widths are close to the ion line spectral widths but that at the higher altitudes of $67-71 \mathrm{~km}$ the PMWE spectral widths are significantly larger than those for the IS ion line. We can interpret this as follows: at lower altitudes the PMWE decay time (and hence the spectral width) is determined by the electron-plasma diffusion time because it is shorter than the wave period, but at the higher altitudes, where the period of incident acoustic waves for matching the radar Bragg scale become smaller, the latter determines the PMWE correlation/decay time (and respectively larger spectral width). For ESRAD measurements, PMWE were observed at 67$72 \mathrm{~km}$ altitudes, where periods for matching incident waves are about the same or shorter than the electron diffusion time (estimated to be about $300 \mathrm{~ms}$ ), and hence these periods determine PMWE spectral widths. Moreover, from Fig. 14 of Kirkwood et al. (2006), one can see that acoustic waves exciting evanescent perturbations which are "visible" for the ESRAD radar have longer periods than those for the EISCAT radar. The wave period $T_{\mathrm{a}}$ is proportional to the radar wavelength $\lambda_{\mathrm{r}}$ squared, and spectral width expressed in velocity units $\left(\mathrm{ms}^{-1}\right)$ should be inversely proportional to $\lambda_{\mathrm{r}}$. Thus at the same altitudes the PMWE spectral width for EISCAT should be $4.3\left(\lambda_{\text {esrad }} / \lambda_{\text {eiscat }} \approx 4.3\right)$ times larger than that for ESRAD given the same ionospheric conditions (e.g. electron and negative ion concentrations). From Fig. 10 the spectral width ratio for PMWE at EISCAT on 11 November and at
ESRAD on 12 November is about 2.5. It might imply that during the measurements the ionospheric conditions at the radar locations were significantly different.

As mentioned in the Introduction there are some experimental indications of the presence of small-sized charged dust, most likely meteoric smoke particles (MSPs), for cases of PMWE (e.g. Belova et al., 2008; Havnes et al., 2011). Calculations by Megner et al. (2008), who combined MSP microphysics with a circulation model, showed also that MSPs of sizes from $0.2 \mathrm{~nm}$ to larger than $3 \mathrm{~nm}$ are expected in relatively high concentrations below $80 \mathrm{~km}$ in non-summer seasons at polar latitudes. The presence of charged dust particles in plasma in amounts comparable to the electron densities will affect electron diffusivity and, hence, IS spectral widths. Positively charged particles and negatively charged large particles (with sizes larger than $1 \mathrm{~nm}$ ) reduce electron diffusivity, which makes the IS spectrum narrower (Cho et al., 1998). In turn, the presence of small negatively charged particles leads to increasing electron diffusivity (as negative ions do in the lower D region), which widens the spectrum. In order to estimate what effect MSPs would have on spectral width for PMWE, one has to know their actual density, sizes and charge state. We have no such information for our cases. Moreover, in general, very little is known about MSP parameters, mainly from a few radar experiments by using indirect methods (e.g. Strelnikova et al., 2007; Havnes et al., 2011) or from numerical modelling (e.g. Megner et al., 2008). However, if PMWE are interpreted as scatter on ion-acoustic highly damped waves in a background dusty plasma, then MSPs should influence spectra inside and outside PMWE layers in the same way. Thus all considerations and conclusions discussed above are valid, at least qualitatively, unless there is an unknown mechanism which is able to confine MSPs in narrow layers coinciding with PMWE layers. So far we do not know of such a mechanism.

Finally, we would like to refer to the recent paper by Strelnikova and Rapp (2013), where statistical analysis of PMWE spectral characteristics has been performed based on $32 \mathrm{~h}$ of EISCAT VHF radar measurements (including 11-12 November 2004). Figure 12 of that paper shows histograms for the spectral widths at the same altitudes inside and outside the PMWE layers. The maxima of these histograms are at the same spectral width value, which implies that, in many cases, the spectral width of PMWE is equal to that of the incoherent scatter. This is an argument in favour of the hypothesis that at least some of the observed PMWE can be associated with ion-acoustic waves. The authors pointed to the fact that the median value of spectral width inside PMWE is larger than that outside the layers, which does not contradict our findings (see Fig. 10). 

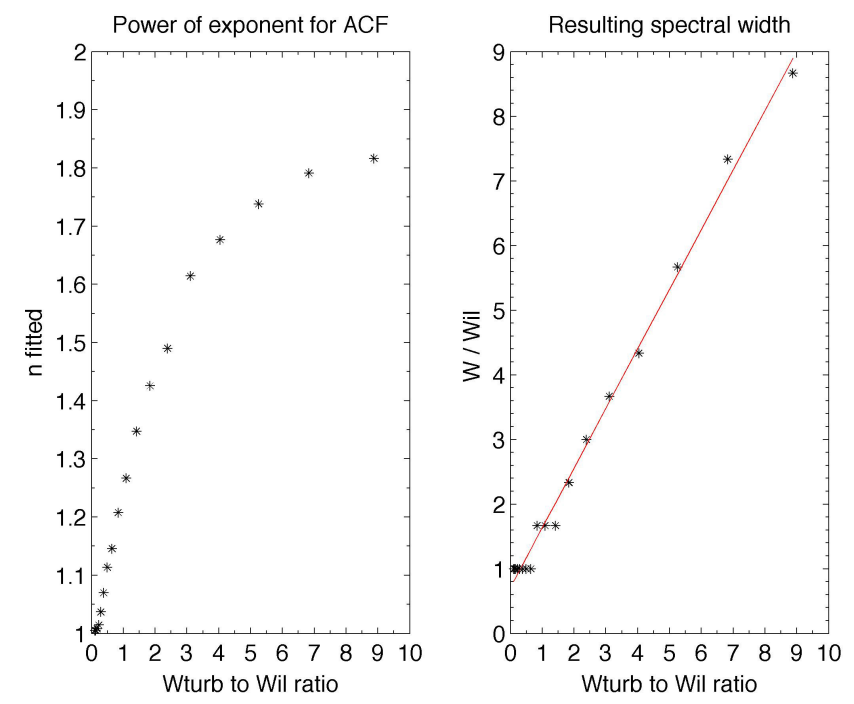

Fig. 11. Left panel: the power of the exponential fit for the ACF resulting from initial Lorentzian spectrum with width $W_{\text {il }}$ plus contribution from the random Doppler velocities representing turbulent velocities with distribution width $W_{\text {turb }}$ as a function of the $W_{\text {turb }}$ to $W_{\mathrm{il}}$ ratio. Right panel: the ratio of the resulting $W$ to initial $W_{\mathrm{il}}$ spectral width as a function of the $W_{\text {turb }}$ to $W_{\mathrm{il}}$ ratio. The red line is a linear fit.

2. EISCAT PMWE ACF shapes are close to Gaussian, implying Gaussian spectra as well.

Lübken et al. (2006) suggested that the turbulent echoes of different strengths might occur at mesospheric altitudes in the wintertime. In order to quantify the effect that the turbulent echoes could have on the observed PMWE spectral widths, we made a model. We start with the exponential ACF with power $n=1$ and the correlation time corresponding to the Lorentzian spectrum (IS ion line) with the spectral width having a value $W_{\mathrm{il}}$ (see Eqs. 4 and 6), apply the Fourier transform and add randomly distributed Doppler (turbulent) velocities (i.e. they have Gaussian distribution with the width $W_{\text {turb }}$ corresponding to the strength of turbulence according to Eq. 13). Then we compute the resulting spectrum and estimate its width $W$. Finally, we apply the inverse Fourier transform to get the resulting $\mathrm{ACF}$ and then fit it by an exponential function with power $n_{\text {fit }}$. We ran the model for different $W_{\text {turb }}$, from values which are much less than $W_{\text {il }}$ and up to values which are several times more than $W_{\mathrm{il}}$. The modelling results are shown in Fig. 11. As can be expected, for the weak turbulence (small $W_{\text {turb }}$ in respect to $W_{\text {il }}$ ) the resulting ACFs are close to the initial Lorentzian one. When $W_{\text {turb }}$ becomes comparable to or larger than $W_{\mathrm{il}}$, the power of the exponent increases and reaches asymptotically the value of 2 ; i.e. the $\mathrm{ACF}$ becomes Gaussian. The resulting spectral width is equal to the initial ion line spectral width $W_{\text {il }}$ for weak turbulence (when $W_{\text {turb }} \leq 0.5 \cdot W_{\text {il }}$ ) and shows linear growth (up to the value $\left.W_{\text {turb }}\right)$ with increasing amplitude of the turbulence.
From Fig. 10 at $67-70 \mathrm{~km}$ altitude, the EISCAT PMWE spectral widths are about $4 \mathrm{~ms}^{-1}$ larger than the $5-6 \mathrm{~ms}^{-1}$ width for the IS ion line (i.e. $W / W_{\mathrm{il}} \approx 1.6-1.8$ ). If we interpret this difference as due to turbulence, then according to Fig. 11, to account for the PMWE observed spectral width, one needs $W_{\text {turb }} \approx 3-4 \mathrm{~m} \mathrm{~s}^{-1}$, corresponding to turbulent dissipation rates $\varepsilon$ of about $100 \mathrm{~mW} \mathrm{~kg}^{-1}$. This is higher than the typical values of $\varepsilon=1-10 \mathrm{~mW} \mathrm{~kg}^{-1}$ for $60-75 \mathrm{~km}$ altitude in winter reported by Lübken (1997), which were based on numerous rocket measurements. (We should mention that the validity of Eq. (13), which relates the spectral width of the radar echo to the turbulent dissipation rate, has been discussed by Strelnikova and Rapp (2013) for the EISCAT VHF radar for the case when MSPs are present. They noted that there is no theoretical justification for the equation in this case. However, they believe that probably some subtle corrections have to be introduced in this equation that will results in slightly smaller $\varepsilon$. Therefore, we may consider our estimates of the turbulent dissipation rate to be valid in the presence of charged dust particles of a few nm radii. This implies that the possible presence of MSPs would not explain significant differences between $\varepsilon$ derived from the PMWE spectral widths and that from the rocket experiments.) To interpret PMWE spectral width for the ESRAD radar, one needs $\varepsilon$ smaller than $10 \mathrm{~mW} \mathrm{~kg}^{-1}$, which is a reasonable value for the winter mesosphere. However if turbulent echoes give the main contribution to the PMWE spectral width, then there should be dependence of this width on the level of turbulence (Hocking, 1985) and, hence, on the echo strength (see Fig. 11). The experimental data show that both EISCAT and ESRAD PMWE spectral widths have only weak or almost no dependence on echo strength (Figs. 6 and 8). Thus, we can conclude that the contribution of turbulence to the PMWE spectral widths, for both EISCAT and ESRAD radars, cannot be convincingly demonstrated. Therefore the Gaussian shape of the PMWE autocorrelation functions and spectra may have another explanation than being of turbulent origin.

There are other cases when spectra of the radar backscattered signal are Gaussian-shaped. For the lower atmosphere it has been found that the majority of power spectra seen by Doppler weather radars are Gaussian (Doviak and Zrnic, 1993). The authors have also shown analytically that, when several independent mechanisms contribute together to broadening spectra, then they are well approximated by a Gaussian function. For the strong echoes in the polar mesosphere in summertime (PMSE) it has been shown that power spectra are Gaussian (Strelnikova and Rapp, 2010, 2011), and therefore they have been assumed to reflect the distribution of turbulent fluctuating velocities. However, Bahcivan et al. (2003) investigated theoretically the scattered field from subsiding turbulent fluctuations and concluded that a Gaussian form of the turbulent spectrum is only one particular case. Other spectral forms, e.g. Lorentzian, can be realised too. Sheth et al. (2006) claimed that no first-principle model exists for the spectrum of mesospheric radar echoes 
and found that the best fit for the spectra for radar returns in Jicamarca, Peru, often gives a power of exponent other than 2 .

In order to know the shape of spectra for the evanescent perturbations we suggested as a possible generation mechanism for PMWE, one should have a theory of radar backscatter from the coherently excited ion-acoustic fluctuations, which is not yet developed. However, we could expect that the shape of the spectrum is not necessarily Lorentzian because the Lorentzian one is a specific shape of IS from thermal ion fluctuations under the diffusion limit, as discussed earlier.

From Fig. 4 one can see that the distribution of the power of the exponent for ACF outside PMWE is rather large and that for some cases the ACF has a Gaussian shape with $n=2$. This may be due to weak, noisy ACFs and also because, at some altitudes, the resulting ACF can be a superposition of those for the conventional IS echo and PMWE, or there may be turbulence affecting the scatter.

\section{Summary}

We have studied spectral characteristics of PMWE measured by two radars, ESRAD at $52 \mathrm{MHz}$ and EISCAT at $224 \mathrm{MHz}$, on 11 and 12 November 2004 during a strong solar proton event. During daytime both radars detected PMWE layers in the altitude range of $65-75 \mathrm{~km}$. For EISCAT it was found that the spectral shape for the echoes inside the PMWE layers is close to Gaussian - in contrast to that outside the layers, which is close to Lorentzian - as for the standard ion line of incoherent scatter. The EISCAT PMWE spectral width has a dependence on altitude: it is about $5-7 \mathrm{~m} \mathrm{~s}^{-1}$ at $64-$ $67 \mathrm{~km}$ and $7-10 \mathrm{~m} \mathrm{~s}^{-1}$ at $68-70 \mathrm{~km}$. At the lower altitudes the PMWE spectral widths are close to those for the IS ion line derived from the EISCAT data outside the layers. At the higher altitudes the PMWE spectra are broader than those for the ion line by $2-4 \mathrm{~m} \mathrm{~s}^{-1}$. Similarly, the ESRAD PMWE spectral widths at $67-72 \mathrm{~km}$ altitude are larger than those for the ion line modelled for the ESRAD radar by $2-4 \mathrm{~m} \mathrm{~s}^{-1}$. If the EISCAT PMWE are explained as turbulent echoes, then strong turbulence dissipation rates of $100 \mathrm{~mW} \mathrm{~kg}^{-1}$ are required in order to account for the observed PMWE spectral widths. These values are somehow larger than those known from the mesospheric climatology based on the rocket data (Lübken, 1997). Additionally, both the ESRAD and EISCAT PMWE spectral widths did not show dependence on the echo strength as would be expected for echoes of turbulent origin. We find the observed spectral characteristics of PMWE for both radars to be consistent with an explanation in terms of evanescent perturbations excited in the electron gas by infrasound waves propagated in the neutral medium from the lower heights as proposed by Kirkwood et al. (2006). However, a complete theory of scatter from this kind of distur- bance needs to be developed before a full conclusion can be made.

\section{Appendix A}

\section{Analysis of the EISCAT data}

In order to get spectral characteristics of echoes, we perform an analysis using autocorrelation functions (ACFs), i.e. in the time domain. The Doppler power spectrum $S$ and ACF are related to each other via the direct or inverse Fourier transform as follows:

$$
\begin{aligned}
S(\omega) & =\int \operatorname{ACF}(\tau) \exp (-i \omega \tau) d \tau \\
\operatorname{ACF}(\tau) & =\frac{1}{2 \pi} \int S(\omega) \exp (i \omega \tau) d \omega
\end{aligned}
$$

If a signal has a Doppler shift $\omega_{\mathrm{D}}=4 \pi / \lambda_{\mathrm{r}} \cdot V_{\mathrm{D}}\left(\lambda_{\mathrm{r}}\right.$ is the radar wavelength) due to radial wind with velocity $V_{\mathrm{D}}$, then

$$
\begin{aligned}
\operatorname{ACF}_{\mathrm{D}} & (\tau)=\frac{1}{2 \pi} \int S\left(\omega+\omega_{\mathrm{D}}\right) \exp (i \omega \tau) d \omega \\
= & \frac{1}{2 \pi} \int S\left(\omega^{\prime}\right) \exp \left(i\left(\omega^{\prime}-\omega_{\mathrm{D}}\right) \tau\right) d \omega^{\prime} \\
= & \frac{1}{2 \pi} \exp \left(-i \omega_{\mathrm{D}} \tau\right) \int S\left(\omega^{\prime}\right)\left(\cos \left(\omega^{\prime} \tau\right)+i \sin \left(\omega^{\prime} \tau\right)\right) d \omega^{\prime} \\
= & \exp \left(-i \omega_{\mathrm{D}} \tau\right)\left[\operatorname{Re}\left(\mathrm{ACF}_{D=0}\right)+i \operatorname{Im}\left(\mathrm{ACF}_{D=0}\right)\right] \\
= & {\left[\cos \left(\omega_{\mathrm{D}} \tau\right) \operatorname{Re}\left(\mathrm{ACF}_{D=0}\right)+\sin \left(\omega_{\mathrm{D}} \tau\right) \operatorname{Im}\left(\mathrm{ACF}_{D=0}\right)\right] } \\
& +i\left[\cos \left(\omega_{\mathrm{D}} \tau\right) \operatorname{Im}\left(\mathrm{ACF}_{D=0}\right)-\sin \left(\omega_{\mathrm{D}} \tau\right) \operatorname{Re}\left(\mathrm{ACF}_{D=0}\right)\right]
\end{aligned}
$$

As a result, the real and imaginary parts of the ACF oscillate with the Doppler frequency. Here $\mathrm{ACF}_{D=0}$ is the ACF for zero Doppler velocity. The real part of $\mathrm{ACF}_{D=0}$ is determined by a decay (correlation) time which defines the spectral width, and the imaginary part of $\mathrm{ACF}_{D=0}$ is determined by asymmetry of the spectrum (with the presence of noise) and is 0 for an ideal spectrum. The real part changes a little from one measurement to another (mainly at the origin $\tau=0$ ), while the imaginary part may change a lot from one spectrum to another and have both positive and negative values.

$$
\begin{aligned}
\operatorname{abs}\left(\operatorname{ACF}_{\mathrm{D}}(\tau)\right) & =\operatorname{abs}\left(\mathrm{ACF}_{D=0}(\tau)\right) \\
& =\sqrt{\operatorname{Re}\left(\mathrm{ACF}_{D=0}(\tau)\right)^{2}+\left(\operatorname{Im}\left(\mathrm{ACF}_{D=0}(\tau)\right)\right)^{2}}
\end{aligned}
$$

The magnitude of the ACF, as one can see from Eq. (A4), is not influenced by the Doppler velocity.

Doppler velocity can be modulated by waves as e.g. $V_{\mathrm{D}}=$ $V_{D 0} \cdot \sin \left(2 \pi / T_{\mathrm{w}} \cdot t+\varphi_{0}\right)$, where $V_{D 0}, T_{\mathrm{w}}$ and $\varphi_{0}$ are the amplitude, period and initial phase of waves, respectively. In order to avoid any influence of waves on the spectral width derivation, one should use the magnitude of the ACF (Eq. A4). 
On 11 November 2004 at heights $60-68 \mathrm{~km}$, a strong wave with $T_{\mathrm{w}}=60-90 \mathrm{~s}$ and $V_{D 0} \approx 15 \mathrm{~m} \mathrm{~s}^{-1}$ was measured with the EISCAT VHF radar (Fig. 2). In the EISCAT arc_dlayer experiment used in our study, the raw experimental ACFs are computed for each $0.17 \mathrm{~s}$ interval with $1.35 \mathrm{~ms}$ resolution and then averaged as complex numbers over $5 \mathrm{~s}$. According to Eq. (A3), each raw ACF has slightly different values due to the presence of the wave, and such an averaging leads to changing correlation time of the resulting ACF and, consequently, to incorrectly estimated spectral width.

We modelled the effect of averaging ACFs over $5 \mathrm{~s}$ dumps on the resulting width of ACF magnitude, using background and wave parameters derived in the experiment. We assumed the magnitudes of the raw ACFs have a Gaussian shape as

$\operatorname{ACF}(\tau)=\mathrm{ACF}_{\tau=0} \cdot \exp \left\{-\left(\tau / \tau_{\mathrm{c}}\right)^{2}\right\}$,

with correlation time $\tau_{\mathrm{c}}$ of 0.04 and $0.02 \mathrm{~s}$ (see Fig. 4) corresponding to half-maximum half-spectral width of about 5 and $9 \mathrm{~m} \mathrm{~s}^{-1}$, respectively. It was found that averaging over a $5 \mathrm{~s}$ dump results in narrowing the ACF width at most by $17 \%$ for the longer correlation time and that changes in the ACF width are negligible for the shorter one. Thus, the expected spectral broadening is $17 \%$ at most (i.e. $0.9 \mathrm{~m} \mathrm{~s}^{-1}$ ).

In order to get a good estimate of ACF correlation time and, hence, spectral width, we have to integrate ACFs calculated for each $5 \mathrm{~s}$ dump, over a relatively long time of several minutes. For each dump, ACFs are modulated by a wave with period of about $1 \mathrm{~min}$, and, as shown before, they might experience different narrowing, which depends on the wave phase at each dump. This should be taken into account when averaging over several dumps. We modelled averaging of ACF magnitude over different time intervals (from tens of seconds to several minutes), assuming $\tau_{\mathrm{c}}=40 \mathrm{~ms}$. It was found that the ACF width decreases by at most $8-9 \%$ and the initial Gaussian shape with the power of the exponent being equal to 2 is distorted to a curve with the power of the exponent of 1.9 .

We can conclude that averaging complex ACFs over $5 \mathrm{~s}$ dumps followed by averaging magnitudes of ACFs over several minutes (finally, we used 10-min integration) with the presence of waves with a period of 60-90 s leads to broadening of spectra by $9 \%$ at the very most for spectral widths of about $5 \mathrm{~m} \mathrm{~s}^{-1}$ and no spectral broadening for spectral widths of about $9 \mathrm{~ms}^{-1}$ or larger.

We applied this method of averaging magnitudes of ACFs (method 1) to the PMWE layer, where the signal is strong enough compare to the noise. Then the real part of the ACFs, containing information about the correlation time of the signal, would make the main contribution when averaged according to Eq. (A4).

However, if we apply Eq. (A4) to the echoes at other altitudes than those for PMWE, i.e. to the background signal, which is the standard ion line of the incoherent scatter, then the signal and noise may be the same order of magnitude.
Then contribution of noise which is squared, i.e. always positive, would grow with an increasing number of integrations (averaging time). Finally, it leads to a distorted shape of the magnitude of the resulting ACF. In order to check this, we applied method 1 to the echoes detected by the EISCAT VHF radar during daytime on 12 November 2004 for the whole altitude range from 60 to $80 \mathrm{~km}$. After averaging over $10 \mathrm{~min}$ the magnitudes of ACFs were approximated by the exponential functions with different parameters as described by Eq. (4). The parameters were estimated by fitting the logarithm of ACFs as shown by Eq. (7). For the echoes outside the PMWE layers the median power of the exponent was found to be 0.1 . This is an unrealistically low value compared to 1 , which is expected for the standard ion line of incoherent scatter at these altitudes (see e.g. Strelnikova and Rapp, 2011). When, for the same echoes outside the PMWE layer, we applied averaging of ACFs as complex numbers, then taking the absolute value (method 2) and after that fitting as described before, the median power of the exponent was estimated to be about 1.2 (Fig. 4). Method 2 should be used for averaging weak signals when there are no waves. Then, according to Eq. (A3), the imaginary parts of ACF (due to noise) of different signs can compensate each other, and the real part (due to signal) will grow. We should mention that we did not find any obvious signature of waves in the background signal, at least at altitudes above the PMWE layers.

Thus, methods 1 and 2 of averaging ACFs for further analysis were applied for the PMWE layers and for the background plasma outside these layers, correspondingly.

Acknowledgements. This research has been partly funded by the Swedish Research Council (grant 621-2010-3218). ESRAD is maintained and operated in collaboration with the Esrange Space Center (SSC). The EISCAT Scientific Association is supported by the research councils of China, Finland, Japan, Norway, Sweden and the UK.

Topical Editor C. Jacobi thanks two anonymous referees for their help in evaluating this paper.

\section{References}

Bahcivan, H., Hysell, D. L., and Kelley, M. C.: Phase diffusion and random walk interpretation of electromagnetic scattering, Phys. Rev. E, 68, 021101, doi:10.1103/PhysRevE.68.021101, 2003.

Banks, P. M. and Kockarts, G.: Aeronomy, Part A, Academic Press, New York, 1973.

Belova, E., Kirkwood, S., Ekeberg, J., Osepian, A., Häggström, I., Nilsson, H., and Rietveld, M.: The dynamical background of polar mesosphere winter echoes from simultaneous EISCAT and ESRAD observations, Ann. Geophys., 23, 1239-1247, doi:10.5194/angeo-23-1239-2005, 2005.

Belova, E., Smirnova, M., Rietveld, M. T., Isham, B., Kirkwood, S., and Sergienko, T.: First observation of the overshoot effect for polar mesosphere winter echoes during radiowave electron temperature modulation, Geophys. Res. Lett., 35, L03110, doi:10.1029/2007GL032457, 2008. 
Blanc, E.: Observations in the upper atmosphere of infrasonic waves from natural or artificial sources: a summary, Ann. Geophys., 3, 673-688, 1985.

Brasseur, G. and Solomon, S.: Aeronomy of the middle atmosphere, D. Reidel Publishing Company, Dordrecht, 1986.

Brattli, A., Blix, T. A., Lie-Svendsen, Ø., Hoppe, U.-P., Lübken, F.-J., Rapp, M., Singer, W., Latteck, R., and Friedrich, M.: Rocket measurements of positive ions during polar mesosphere winter echo conditions, Atmos. Chem. Phys., 6, 5515-5524, doi:10.5194/acp-6-5515-2006, 2006.

Briggs, B. H.: The analysis of spaced sensor records by correlation techniques, MAP Handbook, 13, 166-168, 1985.

Cho, J. Y. N., Sulzer, M. P., and Kelley, M. C.: Meteoric dust effects on D-region incoherent scatter spectra, J. Atmos. Solar-Terr. Phys., 60, 349-357, 1998.

Czechowsky, P., Rüster, R., and Schmidt, G.: Variations of mesospheric structures in different seasons, Geophys. Res. Lett., 6, 459-462, 1979.

Dougherty, J. P. and Farley, D. T.: A theory of incoherent scattering of radio waves by a plasma, Proc. R. Soc. Lond., 259, 79-99, 1960.

Doviak, R. J. and Zrnic, D. S.: Doppler radar and weather observations, Academic Press, 563 p., 1993.

Drob, D. P., Picone, J. M., and Garcés, M. A.: The Global Morphology of Infrasound Propagation, J. Geophys. Res., 108, 4680, doi:10.1029/2002JD003307, 2003.

Ecklund, W. L. and Balsley, B. B.: Long-term observations of the arctic mesosphere with the MST radar at Poker Flat, Alaska, J. Geophys. Res., 86, 7775-7780, 1981.

Havnes, O., La Hoz, C., Rietveld, M. T., Kassa, M., Baroni, G., and Biebricher, A.: Dust charging and density conditions deduced from observations of PMWE modulated by artificial electron heating, J. Geophys. Res., 116, D24203, doi:10.1029/2011JD016411, 2011.

Hedin, A. E.: Extension of the MSIS Thermospheric Model into the Middle and Lower Atmosphere, J. Geophys. Res., 96, 11591172, 1991.

Hocking, W. K.: Measurement of turbulent energy dissipation rates in the middle atmosphere by radar techniques, Radio Sci., 20, 1403-1422, 1985.

Hocking, W. K.: An assessment of the capabilities and limitations of radars in measurements of upper atmosphere turbulence, Adv. Space Res., 17, 37-47, doi:10.1016/0273-1177(95)00728W, 1996.

Hocking, W. K.: Evidence for viscosity, thermal conduction and diffusion waves in the Earth's atmosphere, Rev. Sci. Instr., 74, 420426, 2003.

Holdsworth, D. A., Vincent, R. A., and Reid, I. M.: Mesospheric turbulent velocity estimation using the Buckland Park MF radar, Ann. Geophys., 19, 1007-1017, doi:10.5194/angeo-19-10072001, 2001.

Jackel, B. J.: Characterization of auroral radar power spectra and autocorrelation functions, Radio Sci., 35, 1009-1024, 2000.

Kavanagh, A. J., Honary, F., Rietveld, M. T., and Senior, A.: First observations of the artificial modulation of Polar Mesosphere Winter Echoes, Geophys. Res. Lett,. 33, L19801, doi:10.1029/2006GL027565, 2006.

Kirkwood, S.: Polar Mesosphere WINTER Echoes - a review of recent results, J. Adv. Space Res., 40, 751-757, doi:10.1016/j.asr.2007.01.024, 2007.

Kirkwood, S. and Osepian, A.: Quantitative studies of energetic particle precipitation using incoherent scatter radar, J. Geomag. Geoelectr., 47, 783-799, 1995.

Kirkwood, S., Barabash, V., Belova, E., Nilsson, H., Rao, N., Stebel, K., Blum, U., Fricke, K.-H., Osepian, A., and Chilson, P. B.: Polar mesosphere winter echoes by ESRAD, EISCAT and lidar, Memoirs of the British Astronomical Society, 45, paper 07, September 2002a.

Kirkwood, S., Barabash, V., Belova, E., Nilsson, H., Rao, T. N., Stebel, K., Osepian, A., and Chilson, P. B.: Polar mesosphere winter echoes during solar proton events, Advances in Polar Upper Atmosphere Research, 16, 111-125, 2002b.

Kirkwood, S., Chilson, P., Belova, E., Dalin, P., Häggström, I., Rietveld, M., and Singer, W.: Infrasound - the cause of strong Polar Mesosphere Winter Echoes?, Ann. Geophys., 24, 475-491, doi:10.5194/angeo-24-475-2006, 2006.

Kirkwood, S., Wolf, I., Nilsson, H., Dalin, P., Mikhaylova, D., and Belova, E.: Polar mesosphere summer echoes at Wasa, Antarctica $\left(73^{\circ} \mathrm{S}\right)$ : First observations and comparison with $68^{\circ} \mathrm{N}$, Geophys. Res. Lett., 34, L15803, doi:10.1029/2007GL030516, 2007.

Kirkwood, S., Belova, E., Satheesan, K., Narayana Rao, T., Rajendra Prasad, T., and Satheesh Kumar, S.: Fresnel scatter revisited - comparison of $50 \mathrm{MHz}$ radar and radiosondes in the Arctic, the Tropics and Antarctica, Ann. Geophys., 28, 1993-2005, doi:10.5194/angeo-28-1993-2010, 2010.

Kofman, W., Bertin, F., Röttger, J., Cremieux, A., and Williams, P. J. S.: The EISCAT mesospheric measurements during the CAMP campaign, J. Atmos. Solar Terr. Phys., 46, 565-575, 1984.

La Hoz, C. and Havnes, O.: Artificial modification of Polar Mesospheric Winter Echoes (PMWE) with an RF heater: Do charged dust particles play an active role?, J. Geophys. Res., 113, D19205, doi:10.1029/2008JD010460, 2008.

Lübken, F.-J.: Seasonal variation of turbulent energy dissipation rates at high latitudes as determined by in situ measurements of neutral density fluctuations, J. Geophys. Res., 102, 1344113456, 1997.

Lübken, F.-J., Strelnikov, B., Rapp, M., Singer, W., Latteck, R., Brattli, A., Hoppe, U.-P., and Friedrich, M.: The thermal and dynamical state of the atmosphere during polar mesosphere winter echoes, Atmos. Chem. Phys., 6, 13-24, doi:10.5194/acp-6-132006, 2006.

Mathews, J. D.: The effect of negative ions on collision-dominated Thomson scatter, J. Geophys. Res., 83, 505-512, 1978.

Mathews, J. D. and Tanenbaum, B. S.: A plasma wave and electronplasma diffusion interpretation of Thomson scattering from a plasma containing negative ions, Planet. Space Sci., 29, 335-340, doi:10.1016/0032-0633(81)90021-0, 1981.

Megner, L., Siskind, D. E., Rapp, M., and Gumbel, J.: Global and temporal distribution of meteoric smoke: A twodimensional simulation study, J. Geophys. Res., 113, D03202, doi:10.1029/2007JD009054, 2008.

Moorcroft, D. R.: The shape of auroral backscatter spectra, Geophys. Res. Lett., 31, L09802, doi:10.1029/2003GL019340, 2004.

Müllemann, A. and Lübken, F.-J.: Horizontal winds in the mesosphere at high latitudes, Adv. Space Res., 35, 1890-1894, doi:10.1016/j.asr.2004.11.014, 2005.

Rapp, M. and Lübken, F.-J.: Polar mesosphere summer echoes (PMSE): Review of observations and current understanding, At- 
mos. Chem. Phys., 4, 2601-2633, doi:10.5194/acp-4-2601-2004, 2004.

Sheth, R., Kudeki, E., Lehmacher, G., Sarango, M., Woodman, R., Chau, J., Guo, L., and Reyes, P.: A high-resolution study of mesospheric fine structure with the Jicamarca MST radar, Ann. Geophys., 24, 1281-1293, doi:10.5194/angeo-24-12812006, 2006.

Stebel, K., Blum, U., Fricke, K.-H., Kirkwood, S., Mitchell, N. J., and Osepian, A.: Joint radar/lidar obser vations of possible aerosol layers in the winter mesosphere, J. Atmos. Solar Terr. Phys., 66, 957-970, 2004.

Strelnikova, I. and Rapp, M.: Studies of polar mesosphere summer echoes with the EISCAT VHF and UHF radars: Information contained in the spectral shape, Adv. Space Res., 45, 247-259, doi:10.1016/j.asr.2009.09.007, 2010.

Strelnikova, I. and Rapp, M.: Majority of PMSE spectral widths at UHF and VHF are compatible with a single scattering mechanism, J. Atmos. Solar-Terr. Phys., 73, 2142-2152, doi:10.1016/j.jastp.2010.11.025, 2011.
Strelnikova, I. and Rapp, M.: Statistical characteristics of PMWE observations by the EISCAT VHF radar, Ann. Geophys., 31, 359-375, doi:10.5194/angeo-31-359-2013, 2013.

Strelnikova, I., Rapp, M., Raizada, S., and Sulzer, M.: Meteor smoke particle properties derived from Arecibo incoherent scatter radar observations, Geophys. Res. Lett., 34, L15815, doi:10.1029/2007GL030635, 2007.

Weinstock, J.: Using radar to estimate dissipation rates in thin layers of turbulence, Radio Sci., 16, 1401-1406, 1981.

Zeller, O., Zecha, M., Bremer, J., Latteck, R., and Singer, W.: Mean characteristics of mesosphere winter echoes at midand high-latitudes, J. Atmos. Solar-Terr. Phys., 68, 1087-1104, doi:10.1016/j.jastp.2006.02.015, 2006. 